\section{Use of BIOME-BGG to simulate Mediterranean forest carbon stocks}

\author{
Chiesi $M^{(1)}$, Chirici $G^{(2)}$, Barbati $A^{(3)}$, Salvati $R^{(3)}$, Maselli $F^{(1)}$
}

BIOME-BGC is a bio-geochemical model capable of estimating the water, carbon and nitrogen fluxes and storages of terrestrial ecosystems. Previous research demonstrated that, after proper calibration of its ecophysiological parameters, the model can reproduce the main processes of Mediterranean forest types. The same investigations, however, indicated a model tendency to overestimate woody biomass accumulation. The current paper aims at modifying BIOME-BGC ecophysiological settings to improve the simulation of the woody compartment in Mediterranean forests. The modified ecophysiological parameter is the whole-plant mortality fraction (WPMF), which directly affects the amount of woody biomass stored. The optimal WPMFs of six main forest types in Tuscany are identified by forcing the model to reproduce the maximum standing volumes found in regional and local forest inventories. The effects of this operation are evaluated by comparing the model outputs produced using the original and modified settings to independent measurements from national forest inventories. The results obtained demonstrate the effectiveness of the modifications introduced and consolidate the methodological basis for extending the use of the modeling strategy to other Mediterranean areas.

Keywords: Mediterranean forest, BIOME-BGC, Stem volume, Current annual increment

\section{Introduction}

In the last decades, bio-geochemical models have been used to quantify forest carbon dynamics and monitor the main fluxes and stocks within terrestrial ecosystems (Waring \& Running 2007). These models are based on the current knowledge of major ecological/biophysical processes, but generally suffer from high complexity, difficult calibration and great computational intensity (Chiesi et al. 2007, Liu et al. 1997).

These problems are partly overcome by the BIOME-BGC model (Running \& Hunt 1993) which has been widely applied to

(1) IBIMET-CNR, via Madonna del Piano 10, I-50019 Sesto Fiorentino (FI - Italy); (2) EcoGeoFor - Università del Molise, Contrada Fonte Lappone snc, I-86090 Pesche (IS Italy); (3) DISAFRI - Università della Tuscia, via S. Camillo Lellis snc, I-01100 Viterbo (VT - Italy)

\section{@) Marta Chiesi (m.chiesi@ibimet.cnr.it)}

Received: Jul 12, 2010 - Accepted: Jan 22, 2011

Citation: Chiesi M, Chirici G, Barbati A, Salvati R, Maselli F, 2011. Use of BIOME-BGG to simulate Mediterranean forest carbon stocks. iForest 4: 121-127 [online 2011-0601] URL:

http://www.sisef.it/iforest/show.php? id $=561$ quantify water, carbon and nitrogen cycles in different forest ecosystems (e.g., White et al. lies on a spin-up phase which defines the local equilibrium conditions for some main biome types (e.g., evergreen needle leaf, deciduous broadleaf, etc.). In general, however, the application of BIOME-BGC to specific ecosystems requires a calibration aimed at properly setting its main ecophysiological parameters (Jochheim et al. 2009). This is particularly the case for Mediterranean environments, which are characterized by a high spatial heterogeneity of their main properties and by a marked dryness during part of the growing season (Bolle et al. 2006).

Recent investigations of our research group showed that BIOME-BGC can be efficiently integrated within a more general modeling strategy for the effective simulation of both water and carbon fluxes and storages in Tuscany forests (Maselli et al. 2009, 2010). The same studies, however, indicated a model tendency to overestimate woody biomass stocks, which had already been noted by other authors for different European areas (e.g., Pietsch et al. 2005). This tendency is evidently due to a model deficiency in simulating long-term carbon storages in the woody ecosystem compartment (mostly stems and coarse roots).

The current paper presents an approach to overcome this limitation based on the modi2000, Thornton et al. 2002). This model re- fication of the model parameter settings which regulate these processes. Specifically, a model parameter which controls biomass storage in woody tissues is adjusted to reproduce the maximum standing volumes measured by regional and local forest inventories. The results of this modification are evaluated by comparison with measurements of forest cover (FC) and current annual increments (CAI) derived from independent inventory sources.

The paper first provides a description of the study region (Tuscany, Central Italy) and of the input data-layers. The methodology section then introduces the modeling strategy based on BIOME-BGC and the procedure applied to improve the model parameter settings. The paper is concluded by the presentation of the results achieved and by a discussion section.

\section{Study area}

Tuscany extends over about $9^{\circ}-12^{\circ} \mathrm{E}$ long., $42^{\circ}-44^{\circ} \mathrm{N}$ lat. The topography of the region ranges from flat areas near the coast-line and along the principal river valleys, to hilly and mountainous zones towards the Apennines chain. Approximately $2 / 3$ of the region is covered by hilly areas, $1 / 5$ by mountains and only $1 / 10$ by plains and valleys. From a climatic viewpoint, the climate ranges from typically Mediterranean to temperate warm or cool according to the altitudinal and latitudinal gradients and the distance from the sea (Rapetti \& Vittorini 1995).

Forests cover approximately half of the regional surface and are mainly located over hilly and mountain areas (Fig. 1). The main forest formations are dominated by various oak forest types $(Q$. ilex L., Q. pubescens Willd., $Q$. cerris L.), Mediterranean pines (Pinus pinea L., P. pinaster Ait.), chestnut (Castanea sativa Mill.), beech (Fagus sylvatica L.), silver fir (Abies alba Mill.) and other minor coniferous and deciduous species (Pinus nigra Arnold, Ostrya carpinifolia Scop., Robinia pseudoacacia L., Pseudotsuga menziesii Franco and Cupressus sempervirens $\mathrm{L}$.).

\section{Data sources}

\section{Forest inventory data}

A regional forest inventory (IFT) was carried out in Tuscany during the years 19901998 (Arrigoni et al. 1998). This inventory provided point measurements of all main forest attributes collected over a regular 400 $\mathrm{m}$ spaced grid. Data from other two local inventories are available for the forests of San Rossore (DREAM 2003) and Vallombrosa (Ciancio 2009).

A more recent national forest inventory (INFC), carried out during the years 20002008 , provided similar data aggregated on a 


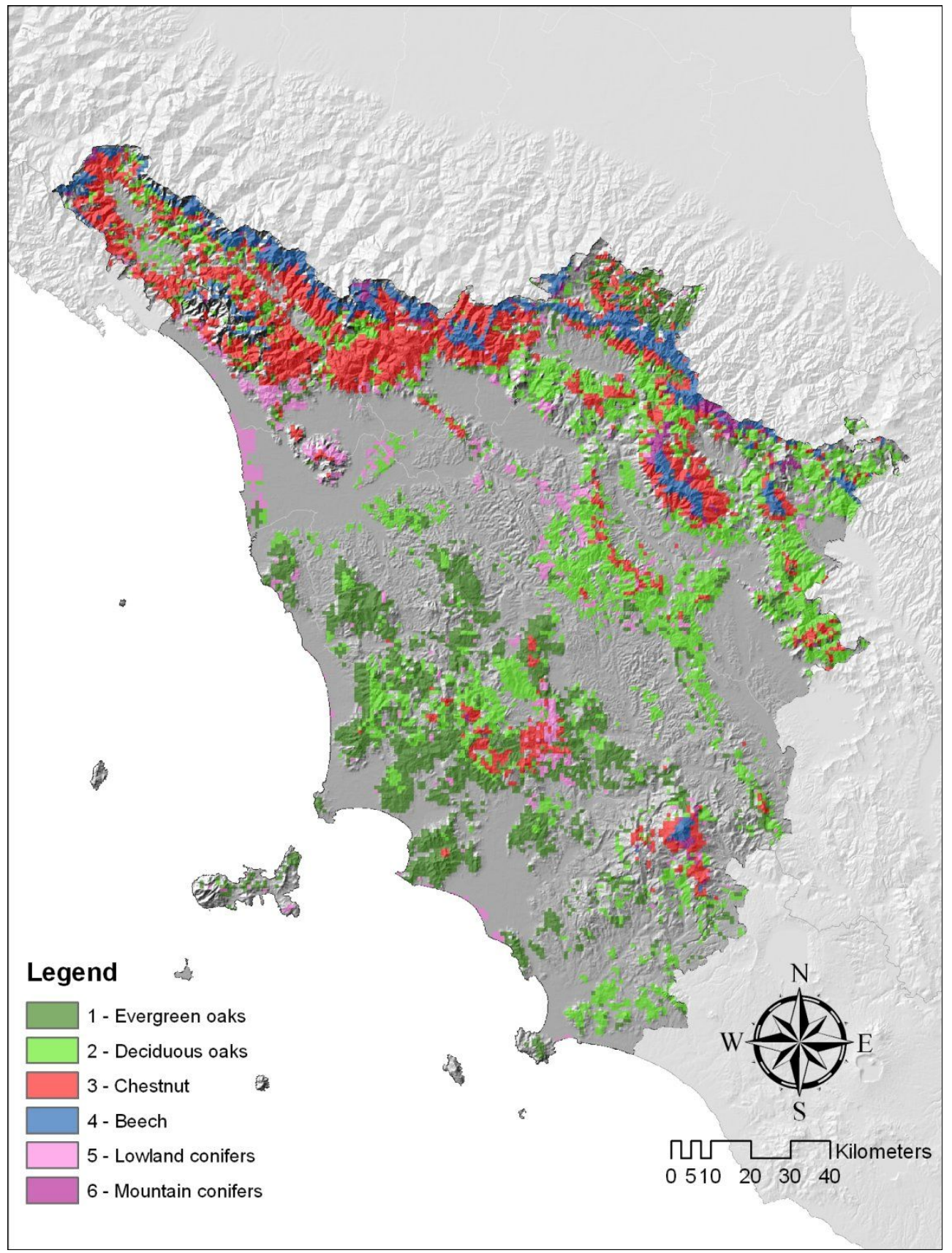

Fig. 1 - Map of Tuscany forests grouped into 6 main forest types (FTs - FT 1: evergreen oaks; FT 2: deciduous oaks; FT 3: chestnut; FT 4: beech; FT 5: lowland conifers; FT 6: mountain conifers), superimposed on a digital illumination model.

regional basis for all main forest types in Italy (Gasparini et al. 2007, 2009).

Additional information was derived from CONECOFOR, a project carried out all over Italy aiming at monitoring the status of forests (Ferretti et al. 2006). In particular, this project reported mean estimates of crown transparency for the main Italian forest classes.

\section{Ancillary data layers}

Daily meteorological data were derived from the Tuscany weather network for the years 1996-2008. Distinctively, daily maximum and minimum temperatures and daily total precipitation were collected from 139 and 179 stations spread all over the regional territory, respectively.

A Digital Terrain Model (DTM) of the study region with $1-\mathrm{km}$ spatial resolution was derived from the Regional Cartographic Service of Tuscany. The same Service provided the digital forest map produced by Arrigoni et al. (1998). This map describes the distribution of 18 different forest classes at 1:250.000 spatial resolution. These classes were regrouped into 6 main forest types (FT) following auto-ecological criteria: evergreen oaks, deciduous oaks, chestnut, beech, lowland conifers and mountain conifers. The main characteristics of the six FTs are shown in Tab. 1.

A regional map of stem volume was produced by Maselli \& Chiesi (2006) by spatia- lizing the measurements of IFT through the processing of Landsat ETM+ images.

Soil information was derived from the Soil Map of Tuscany (1:250.000), produced by the Regional Government during the years 2000-2006 (http://sit.lamma.rete.toscana.it/ websuoli/). This map provided soil depth and texture expressed in sand, silt and clay percentages.

\section{Methodology}

\section{Modeling strategy}

BIOME-BGC is a bio-geochemical model developed at the University of Montana (Running \& Hunt 1993) which is able to estimate the storages and fluxes of water, car- 
bon and nitrogen within numerous terrestrial ecosystems assumed to be homogeneous. The original model does not consider specific species composition, but forests are functionally divided into main biome types: evergreen and deciduous needleleaf forest, and evergreen and deciduous broadleaf forest (White et al. 2000).

The model requires daily meteorological data (minimum and maximum temperature, precipitation, humidity and solar radiation), and a description of site characteristics (e.g., soil depth and texture, altitude, etc.) and of vegetation ecophysiology.

Unlike its precursor FOREST-BGC (Running \& Coughlan 1988), BIOME-BGC does not require information on leaf area index (LAI) of the examined stands: this is a keyvariable which is daily computed and controls the radiation absorption by canopy, water interception, photosynthesis (gross primary production, GPP) and litterfall. The computation of GPP is made by the Farquhar's equation (Farquhar et al. 1980); the net primary production (NPP) is then computed by subtracting the autotrophic respirations (both growth and maintenance respiration). More specifically, growth respiration $\left(\mathrm{R}_{\mathrm{gr}}\right)$ is computed as a function of the amount of carbon allocated to the different pools and maintenance respiration $\left(\mathrm{R}_{\mathrm{mn}}\right)$ is calculated as a function of the tissue temperature and nitrogen concentration. In addition to NPP, BIOME-BGC is able to compute the net ecosystem exchange (NEE) by subtracting the heterotrophic respiration. This represents the loss of carbon from the ecosystem due to decomposition of litter and soil organic matter by microbial activities; it is controlled both by soil temperature and soil moisture (Running \& Hunt 1993).

BIOME-BGC works through a spin-up run which enables to find a quasi-equilibrium condition (sensu Odum 1971) with the local eco-climatic features. To this aim, the model uses the daily meteorological data and the site characteristics to define the initial state variables (i.e., the amount of each carbon and nitrogen pool) of the ecosystem. All estimates provided by the model therefore refer to a forest which is in ecosystem equilibrium condition (sensu Odum 1971). Actually, Tuscany forests are far from this condition due to the effects of the numerous disturbances occurred (e.g., thinning and cutting operations, forestation/deforestation phases, forest fires, etc.), and their processes cannot be directly simulated by BIOME-BGC.

To address this issue, Maselli et al. (2009) proposed to use the ratio between actual and potential forest standing volume as an indicator of ecosystem proximity to equilibrium condition. This ratio can be used to correct the photosynthesis and respiration estimates obtained by the model simulations and compute actual forest NPP $\left(\mathrm{NPP}_{\mathrm{A}}, \mathrm{g} \mathrm{C} \mathrm{m} \mathrm{m}^{-2}\right.$

Tab. 1 - List of the six forest types (FTs) considered with indication of the biome types and of the relevant GPP averages simulated by BIOME-BGC in Tuscany.

\begin{tabular}{cllc}
\hline $\begin{array}{c}\text { Forest } \\
\text { Type }\end{array}$ & $\begin{array}{c}\text { Dominant } \\
\text { forest species }\end{array}$ & $\begin{array}{c}\text { Biome type } \\
\text { (sensu } \text { BIOME-BGC) }\end{array}$ & $\begin{array}{c}\text { GPP } \\
\left(\mathbf{g ~ C} / \mathbf{m}^{2} / \mathbf{y e a r}\right)\end{array}$ \\
\hline 1 & Evergreen oaks & Evergreen broadleaf forest & 1238 \\
2 & Deciduous oaks & Deciduous broadleaf forest & 1288 \\
3 & Chestnut & Deciduous broadleaf forest & 1170 \\
4 & Beech & Deciduous broadleaf forest & 1016 \\
5 & Lowland conifers & Evergreen needleleaf forest & 1378 \\
6 & Mountain conifers & Evergreen needleleaf forest & 1200 \\
\hline
\end{tabular}

month $^{-1}$ ) as follows (eqn. 1):

$$
N P P_{A}=G P P \cdot F C_{A}-F C_{A}-R m n \cdot N V_{A}
$$

where $G P P, R g r$ and $R m n$ correspond, respectively, to the $G P P$, growth and maintenance respirations estimated by BIOME-BGC ( $\mathrm{g} \mathrm{C} \mathrm{m}^{-2}$ month $\left.^{-1}\right)$, and the two terms $F C_{\mathrm{A}}$ (actual forest cover) and $N V_{\mathrm{A}}$ (actual normalized standing volume), both dimensionless, are derived from the ratio between actual and potential stem volumes through the following equations (Maselli et al. 2009 - eqn. 2, eqn. 3):

$$
\begin{gathered}
N V_{A}=\frac{V o l_{A}}{V o l_{\text {max }}} \\
F C_{A}=1-\exp ^{\left(-N V_{A} \cdot L A I_{\max }\right)}
\end{gathered}
$$

where $V o l_{\mathrm{A}}$ is actual (measured) standing volume, and $V o l_{\max }$ and $L A I_{\max }$ are the potential (maximum) standing volume and LAI corresponding to ecosystem equilibrium condition. While $L A I_{\max }$ is directly provided by BIOME-BGC, $V o l_{\max }$ can be computed as follows (eqn. 4):

$$
\text { Vol }_{\max }=\text { Stem } C / B W D / B E F / 0.5 \cdot 100
$$

where Stem $C$ is the maximum stem carbon ( $\mathrm{g}$ $\mathrm{C} \mathrm{m}^{-2}$ ) simulated by BIOME-BGC, BEF is

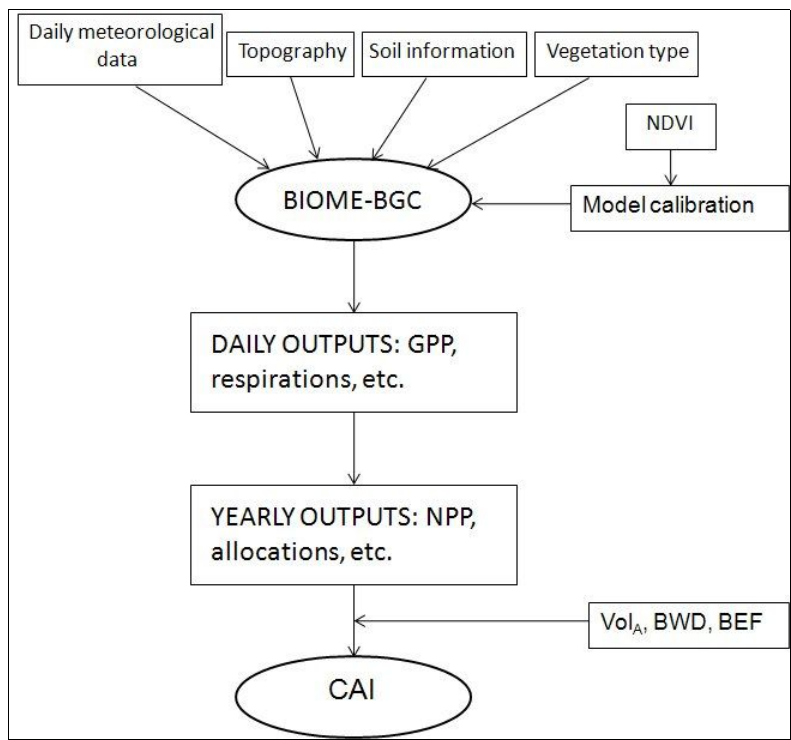

the volume of above ground biomass/ standing volume, Biomass Expansion Factor (dimensionless), and $B W D$ is the Basic Wood Density $\left(\mathrm{Mg} \mathrm{m}^{-3}\right)$. The values of $B E F$ and $B W D$ are taken from Federici et al. (2008). The factors 0.5 and 100 are respectively applied to convert from carbon to dry matter content and from $\mathrm{g} \mathrm{m}^{-2}$ to $\mathrm{Mg} \mathrm{ha}^{-1}$.

As can be easily understood, the maximum stem $\mathrm{C}$ simulated by BIOME-BGC directly affects the estimated $\mathrm{NV}_{\mathrm{A}}$ and $\mathrm{FC}_{\mathrm{A}}$ and, consequently, the predicted $\mathrm{NPP}_{\mathrm{A}}$. Hence, its correct estimation for each FT is crucial for an accurate prediction of actual forest structure and functions, and, particularly, for the simulation of net carbon fluxes.

\section{Modification of BIOME-BGC mortality settings}

The model parameter settings provided by White et al. (2000) had already been adapted to reproduce the behaviour of Mediterranean forest species in Tuscany (see Chiesi et al. 2007, Maselli et al. 2009). Even though the calibrated model produced good estimates of the main terms of the carbon cycle (i.e., GPP, NPP and NEE) (e.g., Chiesi et al. 2007, 2010), it tended to overestimate the forest standing biomass measured by ground surveys (Maselli et al. 2010). A similar conclusion was drawn by Pietsch et al. (2005) after applying the original BIOME-BGC ver-
Fig. 2 - Simplified scheme of the modeling steps followed to obtain CAI estimates starting from the input data. 


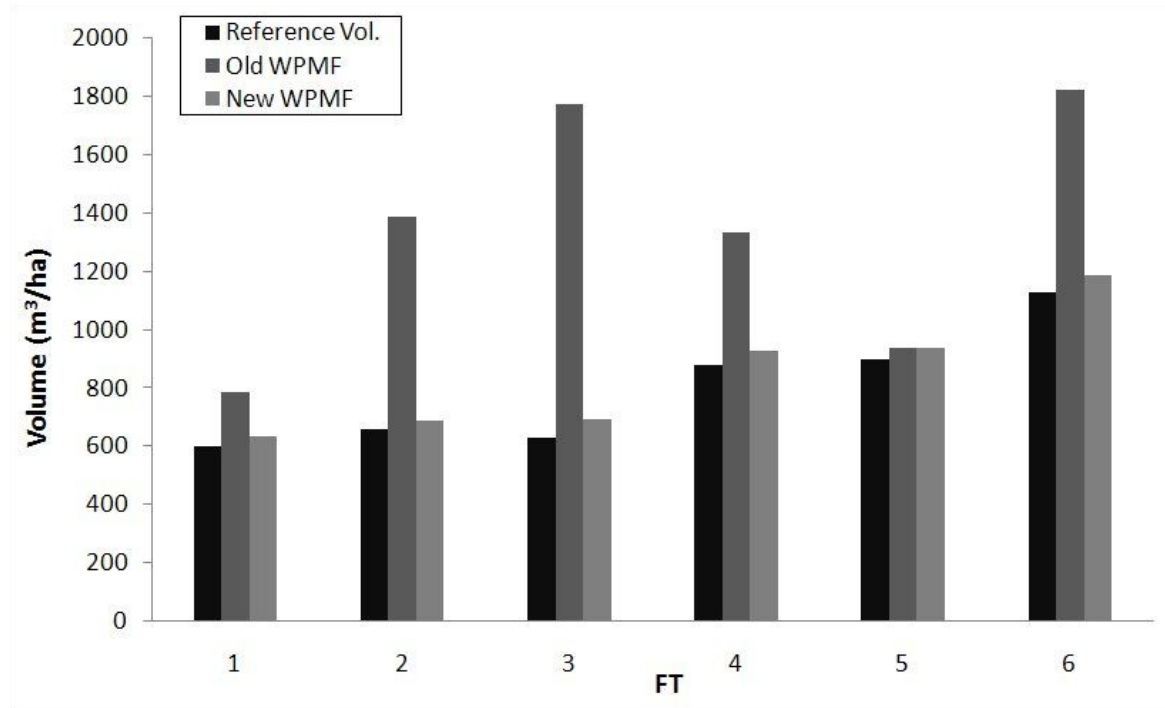

Fig. 3 - Comparison between the reference volumes of the 6 FTs and the volumes estimated using the original and the new WPMFs.

sion to simulate the behavior of major forest species in Central Europe (i.e., beech, oaks and larch).

To address this issue the BIOME-BGC parameter settings of the six Tuscany forest types were further modified. In particular, attention was focused on the whole annual plant mortality fraction (WPMF), which represents the fraction of the above- and below-ground ecosystem carbon pools that are removed and sent to the litter compartments over the course of each simulation year. By this mechanism woody material (live and dead) does not accumulate within the tree pools and becomes available for the decomposition process. This mortality rate includes both natural tree mortality and mortality due to natural disturbances such as wind-throw. According to the BIOME-BGC logic, this parameter influences the amount of woody biomass that is accumulated yearly (White et al. 2000). Consequently, changes of WPMF modify the plant carbon stocks (mainly stem and coarse root carbon stocks) without substantially altering all other pools, which are constrained by higher turn-over rates (White et al. 2000). Due to the same logic, WPMF changes do not significantly alter all main BIOME-BGC photosynthesis and respiration estimates (Tatarinov \& Cienciala 2006).

The application of the modeling strategy to Tuscany forests required the use of daily meteorological data (minimum and maximum temperatures, precipitation and solar radiation) for each $1-\mathrm{km}^{2}$ pixel. To this aim, the daily temperature and rainfall data were extended from the weather stations to the regional surface by means of the DAYMET algorithm (Thornton et al. 2000). Solar radiation and humidity were then estimated by the use of MT-CLIM (Thornton et al. 1997). These meteorological data layers, joint to layers descriptive of forest and soil properties, were used to drive the conventional application of BIOME-BGC on a per-pixel basis (see Chiesi et al. 2010 for details).

After this first run, the maximum standing volumes which are reasonable for the six forest types in Tuscany were identified using the point measurements of IFT and of the other two local forest inventories (San Rossore and Vallombrosa). In particular, the

Tab. 2 - Definitive BIOME-BGC parameter settings. Only the model parameters changed with respect to default values are reported. The parameters controlling conductance reduction (leaf water potential and vapour pressure deficit) were reduced to $90 \%$ of the default values for the first three ecosystems and were left unchanged for the others. The last column reports the new WPMFs, which replace the default settings $\left(0.0051 \mathrm{yr}^{-1}\right)$ proposed by White et al. (2000) for all forest types.

\begin{tabular}{cccc}
\hline $\begin{array}{c}\text { Ecosystem } \\
\text { type }\end{array}$ & $\begin{array}{c}\text { Maximum stomatal } \\
\text { conductance }\left(\mathbf{m ~ s}^{-\mathbf{1}}\right)\end{array}$ & $\begin{array}{c}\text { Fraction of leaf } \\
\mathbf{N} \text { in Rubisco }\end{array}$ & $\begin{array}{c}\text { New WPMF } \\
\left(\mathbf{1} \text { yr } \mathbf{r}^{-1}\right)\end{array}$ \\
\hline 1 & 0.0016 & 0.029 & 0.00625 \\
2 & 0.0020 & 0.090 & 0.01 \\
3 & 0.0023 & 0.078 & 0.0125 \\
4 & 0.0045 & 0.090 & 0.01 \\
5 & 0.0024 & 0.022 & 0.005 \\
6 & 0.0032 & 0.027 & 0.01 \\
\hline
\end{tabular}

maximum volumes found by these inventories for each FT were conservatively considered to be $90-95 \%$ of the volumes which could be potentially sustained by the corresponding sites. The WPMFs of the six forest types were therefore iteratively modified until the standing volumes predicted by eqn. 4 for the corresponding sites exceeded the IFT volume measurements of $5-10 \%$. Next, the model version with the new WPMF settings was reapplied to simulate the behavior of all forest areas in Tuscany.

Validation of BIOME-BGC outputs

The effect of changing the BIOME-BGC WPMF settings was evaluated by comparing the accuracy of the actual forest cover $\left(\mathrm{FC}_{\mathrm{A}}\right)$ and current annual increment (CAI) estimates before and after the modification against independent regional measurements.

As regards the first test, $\mathrm{FC}_{\mathrm{A}}$ estimates were computed by feeding eqn. 3 with BIOMEBGC outputs and the regional INFC volume averages of the six FTs. The $\mathrm{FC}_{\mathrm{A}}$ estimates obtained were validated against INFC canopy cover measurements corrected for the mean crown transparencies derived from CONECOFOR, an intensive monitoring programme of forest ecosystems in Italy ( $\mathrm{CON}$ trollo ECOsistemi FORestali - Ferretti et al. 2006).

For the second test, the $\mathrm{NPP}_{\mathrm{A}}$ estimates of the six FTs were calculated by feeding eqn. 1 with the same data. From these estimates, relevant CAI values $\left(\mathrm{m}^{3} \mathrm{ha}^{-1}\right.$ year $\left.{ }^{-1}\right)$ were obtained through the following equation (eqn. 5):

$$
C A I=N P P_{A}+S C A / B E F / B W D \cdot 2 \cdot 100
$$

where $B E F$ and $B W D$ are the same as for eqn. 4 and $S C A$ is the Stem C Allocation ratio of BIOME-BGC. These estimates were directly compared to the CAI measurements provided by INFC. A simplified scheme of the steps followed to estimate CAI is indicated in Fig. 2.

Both comparisons were made using the available aggregated data for the six forest types of Tuscany. The overall estimation accuracy over the six FTs was summarized by means of common statistics (i.e., correlation coefficient: $r$; root mean square error: RMSE; and mean bias error: MBE).

\section{Results}

Reproduction of IFT maximum volumes

The last column of Tab. 1 reports the average GPP values estimated for the six Tuscany FTs using BIOME-BGC with the original parameter settings. These GPPs generally follow the auto-ecological characteristics of the ecosystems: the lowest values are typical for mountain forests (FT 4 for broadleaves and FT 6 for conifers), while 


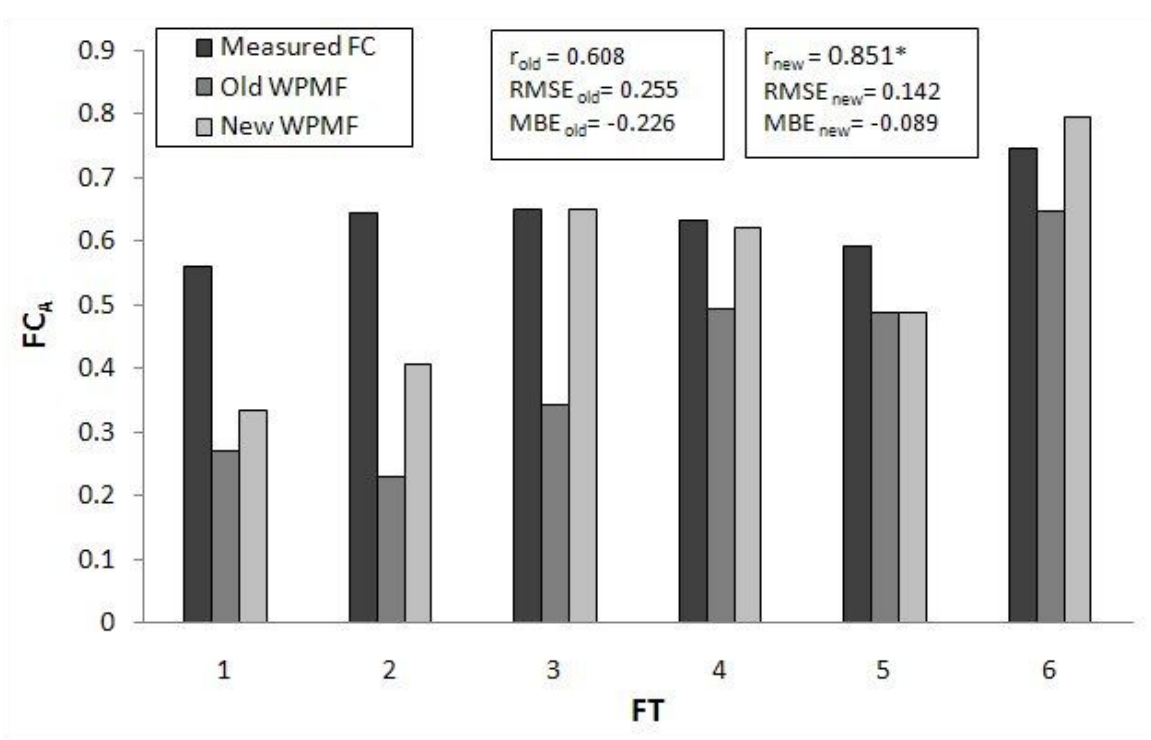

Fig. 4 - Comparison between actual forest cover $\left(\mathrm{FC}_{\mathrm{A}}\right)$ measured and estimated by the old and the new versions of BIOME-BGC. $\left({ }^{*}\right)$ : significant correlation, $\mathrm{P}<0.05$.

highest productions are found for lowland coniferous species. These GPPs are also in accordance with the measurements obtained by the eddy correlation technique (Maselli et al. 2009).

As regards the carbon stocks estimates, they only partly follow these GPP patterns, due to the different respiration and allocation of the six forest types (Fig. 3). The potential volume estimates are generally higher than the maximum IFT measurements for most FTs. Small differences are found for FT 1 and FT 5, while for FT 2, FT 3, FT 4 and FT 6 the overestimation is very high.

In almost all cases the new WPMFs identified by the current investigation (Tab. 2) are higher than the originals, which implies that

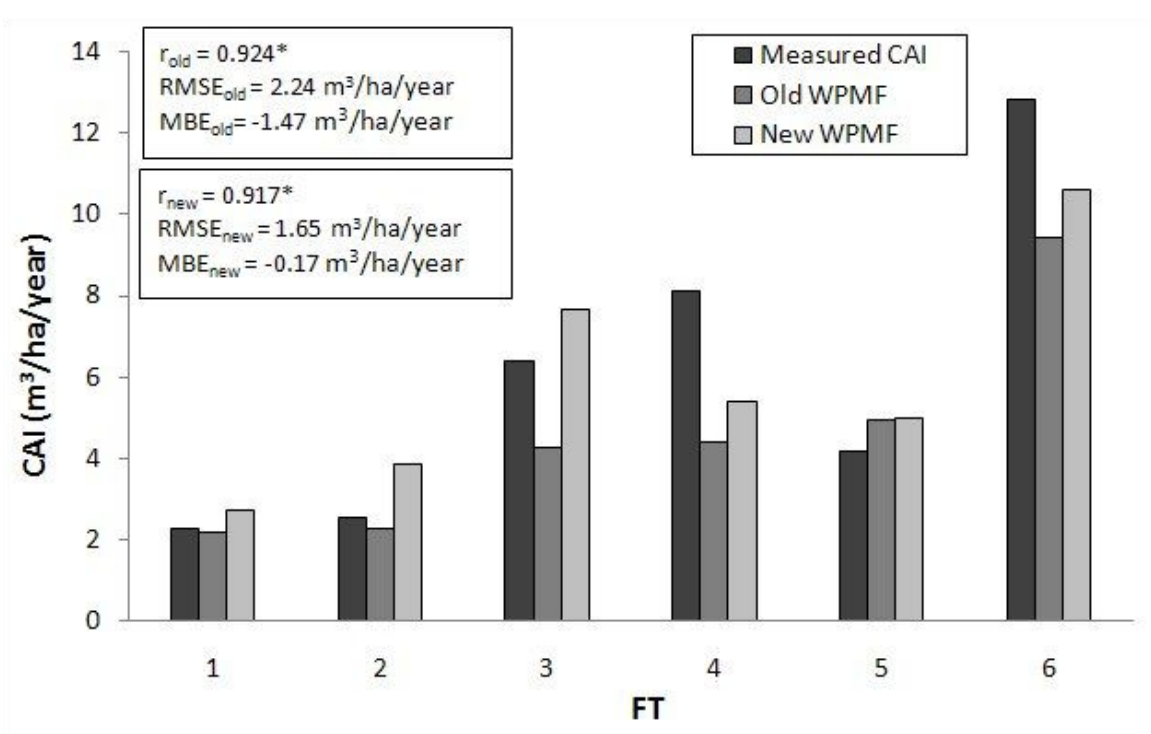

Fig. 5 - Comparison between current annual increments (CAI) measured and estimated by the old and the new versions of BIOME-BGC. $\left({ }^{*}\right)$ : significant correlation, $\mathrm{P}<0.05$. in Fig. 4 and Fig. 5 together with relevant ground measurements. As regards $\mathrm{FC}_{\mathrm{A}}$, the estimates obtained with the original WPMFs are much lower than the measurements for FT 1 and 2. In the other cases, minor but still significant differences are observed. The use of the new WPMFs strongly reduces the $\mathrm{FC}_{\mathrm{A}}$ underestimation for the first two FTs, and improves the estimation accuracy also for FT 4 and 6. Overall, this modification results in a notable increase of the correlation coefficient and in a significant reduction in the mean differences between the measured and estimated $\mathrm{FC}_{\mathrm{A}}$ values.

The comparison between measured and estimated CAIs provides similar results. The model with the original WPMFs strongly underestimates INFC CAIs for FT 3, 4 and 6. This problem is partly corrected by the use of the new WPMFs, with the highest improvement obtained for FT 3. As a consequence, the new WPMF settings lead to a substantial reduction of the mean errors: $\mathrm{RMSE}_{\text {old }}=2.24 \mathrm{~m}^{3} \mathrm{ha}^{-1}$ year $^{-1}$ and $\mathrm{MBE}_{\text {old }}=$ $-1.47 \mathrm{~m}^{3} \mathrm{ha}^{-1}$ year $^{-1}$ against $\mathrm{RMSE}_{\text {new }}=1.65$ $\mathrm{m}^{3} \mathrm{ha}^{-1}$ year ${ }^{-1}$ and $\mathrm{MBE}_{\text {new }}=-0.17 \mathrm{~m}^{3} \mathrm{ha}^{-1}$ year ${ }^{-1}$. and coarse roots for a lower number of years. Exceptions are represented by FT 1, for which WPMF is slightly increased, and FT 5 , for which WPMF is unvaried. These WPMF changes have direct consequences on the potential volumes simulated by BIOMEBGC (Fig. 3), while do not introduce significant differences in the predicted GPP (differences lower than $2 \%$ ): the same is true for all respirations and LAI.

\section{Simulation of mean canopy covers and CAIs}

The mean $\mathrm{FC}_{\mathrm{A}}$ and CAI values of the six forest types measured and estimated before
and after the WPMF modification are shown

\section{Discussion and conclusion}

BIOME-BGC has been shown to be applicable to simulate the behaviour of a wide variety of forest ecosystems, both in terms of eco-physiological processes and accumulated carbon pools (e.g., Pietsch et al. 2005, Maselli et al. 2009, etc.). Previous investigations in various European forest areas, however, indicated a model tendency to overestimate the stored carbon stocks (e.g., Pietsch et al. 2005, Maselli et al. 2010). Specifically, the maximum (potential) standing volumes simulated by the model are mostly higher than the volumes which can be actually found in most European forests. This implies errors in the simulation of net carbon accumulation processes which, in some cases, have been fixed empirically (Maselli et al. 2010).

The current paper proposes a more sound approach to address this problem. This approach is based on the modification of a major parameter setting which controls carbon accumulation in the vegetation compartment, WPMF (Tatarinov \& Cienciala 2006). The modification is performed by taking as reference values the maximum standing volumes derived from various forest inventories. This operation relies on the evidence that these inventories provide a large number of point measurements for each FT, which should guarantee the representativeness of the volumes found for production conditions close to the potential maxima and not significantly limited by occurred disturbances. The alternative use of parametric methods for the identification of these potential volumes (i.e., using standard deviation intervals from 
volume averages) has been found to be currently unfeasible, due to the marked nonnormality of the volume statistical distributions.

The application of the current method yields new WPMFs which are not descriptive of the ages reachable by the six forest types in all conditions. In fact, the WPMFs identified are related to the average turn-over times which would characterize the existing forests in the absence of disturbing factors. Consequently, these WPMFs are dependent on local environmental factors (fertility, climate, growth form, etc.), and are not directly exportable to all other cases.

As expected, the use of new WPMFs does not modify the original LAI, GPP and respiration estimates but leads to substantial changes in accumulated stem carbon. The new volume averages of the six forest types are mostly lower than the original values and more consistent than these with the estimates provided by different sources (DREAM 1994, 1996).

The WPMF modification results in a marked improvement in the reproduction of the carbon stocks stored in the woody ecosystem compartment. This improvement is decisive in enhancing the assessment of $\mathrm{NV}_{\mathrm{A}}$ and $\mathrm{FC}_{\mathrm{A}}$. As a consequence, the modification implies a substantial enhancement in the estimation of net production processes (i.e., woody NPP).

These results are particularly relevant when considering that all model simulations have been performed over forests which are very heterogeneous due to the variable climate and site factors and to the different management practices which characterize Tuscany environments. It can therefore be concluded that the use of the new BIOME-BGC versions can significantly enhance the capacity of the modeling strategy to simulate carbon stocks and fluxes across a variety of Mediterranean forest ecosystems.

\section{Acknowledgements}

The work was partially carried out under the C_FORSAT project "Modelling the carbon sink in Italian forest ecosystems using ancillary data, remote sensing data and productivity models" (national coordinator: Prof. G. Chirici), funded by the FIRB2008 program of the Italian Ministry of University and Research (RBFR08LM04).

The authors thank Dr. M. Moriondo, Dr. L. Fibbi and Prof. M. Bindi for their assistance in the calibration and application of BIOMEBGC in Tuscany, and Prof. P. Corona for his precious comments on the subject of the paper.

\section{References}

Arrigoni PV, Raffaelli M, Rizzotto M, Selvi F, Viciani D, Lombardi L, Foggi B, Melillo C, Benesperi R, Ferretti G, Benucci S, Turrini S, di Tom- maso PL, Signorini M, Bargelli E, Miniati U, Farioli C, de Dominicis V, Casini S, Chiarucci A, Tomei PE, Ansaldi M, Maccioni S, Guazzi E, Zocco Pisana L, Cenerini A, Dell'Olmo L, Menicagli E (1998). La vegetazione forestale. Serie boschi e macchie di Toscana. Regione Toscana, Giunta regionale, Firenze, Italy, pp. 215.

Bolle HJ, Eckardt M, Koslowsky D, Maselli F, Melia-Miralles J, Menenti M, Olesen FS, Petkov L, Rasool I, Van de Griend A (2006). Mediterranean land-surface processes assessed from space. Regional Climate Studies, vol. XXVIII, Springer, Berlin, Germany, pp. 760.

Chiesi M, Maselli F, Moriondo M, Fibbi L, Bindi M, Running SW (2007). Application of BIOMEBGC to simulate Mediterranean forest processes. Ecological Modelling 206: 179-190. - doi: 10.1016/j.ecolmodel.2007.03.032

Chiesi M, Moriondo M, Maselli F, Gardin L, Fibbi L, Bindi M, and Running SW (2010). Simulation of mediterranean forest carbon pools under expected environmental scenarios. Canadian Journal of Forest Research 40: 850-860. doi: 10.1139/X10-037

Ciancio O (2009). Piano di gestione e silvomuseo 2006-2025. Riserva naturale statale biogenetica di Vallombrosa. Corpo Forestale dello Stato, Firenze, Italy, pp. 438.

DREAM (1994). Complesso forestale Le CarlineLa Selva: piano di assestamento forestale 19942004. Regione Toscana, Pistoia, Italy.

DREAM (1996). Piano generale di gestione del Complesso Forestale Regionale Giogo-Casaglia per il periodo 1996-2015. Regione Toscana, Italy.

DREAM (2003). Tenuta di San Rossore. Note illustrative della carte forestale e della fruizione turistica. S.E.L.C.A., Firenze, Italy.

Farquhar GD, von Caemmerer S, Berry JA (1980). A biochemical model of photosynthetic $\mathrm{CO}_{2}$ assimilation in leaves of $\mathrm{C}_{3}$ species. Planta 149: 78-90. - doi: 10.1007/BF00386231

Federici S, Vitullo M, Tulipano S, De Lauretis R, Seufert G (2008). An approach to estimate carbon stocks change in forest carbon pools under the UNFCCC: the Italian case. iForest 1: 86-95. doi: 10.3832/ifor0457-0010086

Ferretti M, Petriccione B, Bussotti F, Fabbio G (2006). Ecological condition of selected forest ecosystems in Italy. Status and changes 19952005. Annali del Centro di Ricerca per la Selvicoltura, vol. 34 , pp. 56

Gasparini P, De Natale F, Di Cosmo L, Gagliano C, Salvadori I, Tabacchi G, Tosi V (2007). INFC 2007 - I caratteri quantitativi 2005 - parte 1. MiPAAF, Ispettorato Generale Corpo Forestale dello Stato, CRA-MPF, Trento, Italy.

Gasparini P, Bertani R, De Natale F, Di Cosmo L, Pompei E (2009). Quality control procedures in the Italian national forest inventory. Journal of Environmental Monitoring 11: 761-768. - doi: $10.1039 / \mathrm{b} 818164 \mathrm{k}$

Jochheim H, Puhlmann M, Beese F, Berthold D, Einert P, Kallweit R, Konopatzky A, Meesenburg H, Meiwes K-J, Raspe S, Schulte-Bisping H, Schulz (2009). Modelling the carbon budget of intensive forest monitoring sites in Germany using the simulation model BIOME-BGC. iForest 2: 7-10. - doi: 10.3832/ifor0475-002 Liu J, Chen JM, Cihlar J and Park WM (1997). A process-based Boreal Ecosystem Productivity Simulator using remote sensing inputs. Remote Sensing of Environment 62: 158-175. - doi: 10.1016/S0034-4257(97)00089-8

Maselli F, Chiesi M (2006). Evaluation of statistical methods to estimate forest volume in a Mediterranean region. IEEE Transactions on Geoscience and Remote Sensing 44 (8): 22392250. - doi: 10.1109/TGRS.2006.872074

Maselli F, Chiesi M, Moriondo M, Fibbi L, Bindi M, Running SW (2009). Integration of ground and satellite data to simulate the forest carbon budget of a Mediterranean region. Ecological Modelling 220: 330-342. - doi: 10.1016/j.ecolmodel.2008.10.002

Maselli F, Chiesi M, Barbati A, Corona P (2010). Modelling forest net primary production by the integration of multisource ground and remote sensing data. Journal of Environmental Monitoring 12: 1082-1091. - doi: 10.1039/b924629k Odum EP (1971). Fundamentals of Ecology ( $3^{\text {rd }}$ edn.). W. B. Saunders, Philadelphia, USA.

Pietsch SA, Hasenauer H, Thornton PE (2005). BGC-model parameters for tree species growing in central European forests. Forest Ecology and Management 211: 264-295. - doi: 10.1016/j.foreco.2005.02.046

Rapetti F, Vittorini S (1995). Carta climatica della Toscana. Pacini Editore, Pisa, Italy.

Running SW, Hunt ER (1993). Generalization of a forest ecosystem process model for other biomes, BIOME-BGC, and an application for global-scale models. In: "Scaling physiological processes: leaf to globe" (Ehleringer JR, Field CB eds). Academic Press, San Diego, CA, USA, pp. 141-158.

Tatarinov FE, Cienciala I (2006). Application of BIOME-BGC model to managed forests. 1. Sensitivity analysis. Forest Ecology and Management 237: 267-279 - doi: 10.1016/j.foreco.2006. 09.085

Thornton PE, Running SW, White MA (1997). Generating surfaces of daily meteorological variables over large regions of complex terrain. Journal of Hydrology 190: 214-251. - doi: 10.1016/S0022-1694(96)03128-9

Thornton PE, Law BE, Gholz HL, Clark KL, Falge E, Ellsworth DS, Goldstein AH, Monson RK, Hollinger D, Falk M, Chen J, Sparks JP (2002). Modeling and measuring the effects of disturbance history and climate on carbon and water budgets in evergreen needleleaf forests. Agricultural and Forest Meteorology 113: 185 222. - doi: 10.1016/S0168-1923(02)00108-9

Thornton PE, Hasenauer H, White MA (2000). Simultaneous estimation of daily solar radiation and humidity from observed temperature and precipitation: an application over complex terrain in Austria. Agricultural and Forest Meteorology 104: 255-271. - doi: 10.1016/S0168-1923 (00)00170-2

Running SW, Coughlan JC (1988). A general 
model of forest ecosystem processes for regional applications. I. Hydrologic balance, canopy gas exchange and primary production processes. Ecological Modelling 42: 1425-154. - doi: 10.1016/0304-3800(88)90112-3
Waring HR, Running SW (2007). Forest Ecosystems. Analysis at multiples scales. $2^{\text {nd }}$ edition. Academic Press, San Diego, pp. 55.

White MA, Thornton PE, Running SW, Nemani RR (2000). Parameterisation and sensitivity ana- lysis of the BIOME-BGC terrestrial ecosystem model: net primary production controls. Earth Interactions 4: 1-85. - doi: 10.1175/10873562(2000)004<0003:PASAOT $>2.0 . \mathrm{CO} ; 2$ 